\title{
Associations between site of skin lesions and depression, social anxiety, body-related emotions and feelings of stigmatization in psoriasis patients
}

\author{
Patryk Łakuta ${ }^{1,2}$, Kamil Marcinkiewicz ${ }^{3}$, Beata Bergler-Czop ${ }^{4}$, Ligia Brzezińska-Wcisło ${ }^{4}$, Anna Słomian ${ }^{5}$ \\ ${ }^{1}$ Department of Psychology, SWPS University of Social Sciences and Humanities, Warsaw, Poland \\ ${ }^{2}$ Institute of Psychology, University of Silesia, Katowice, Poland \\ ${ }^{3}$ Department of Cardiology, Institute of Cardiology, Warsaw, Poland \\ ${ }^{4}$ Department of Dermatology, Medical University of Silesia, Katowice, Poland \\ ${ }^{5}$ Group of Provincial Psychological Outpatients Clinics, Katowice, Poland
}

Adv Dermatol Allergol 2018; XXXV (1): 60-66

DOI: https://doi.org/10.5114/pdia.2016.62287

\begin{abstract}
Introduction: Research has demonstrated a link between psoriasis and a multitude of psychological impairments; however, relatively few studies have examined the importance of site of skin lesions for negative psychological outcomes in psoriasis patients.

Aim: To investigate relationships between anatomical location of psoriatic lesions and experiences of stigmatization, negative emotional attitude towards the body, depression and social anxiety.

Material and methods: Adult psoriasis patients $(N=193)$ completed the Stigmatization Scale, the Body Emotions Scale, the Beck Depression Inventory and the Social Anxiety Questionnaire. The body surface area index was used to assess the location and extent of psoriasis.

Results: Feelings of stigmatization were found to be most closely related to the presence of psoriatic lesions on the chest, and the arms and hands. Higher levels of social anxiety were found to be most closely related to the location of psoriatic lesions on the head and neck. Negative emotional attitude towards the body was found to be most closely related to the location of psoriatic lesions on the arms and hands, and on the head and neck. Higher levels of depressive symptoms were most closely related to the presence of psoriatic lesions on the head and neck, the arms and hands, and the genital area.

Conclusions: The presence of psoriatic lesions on the head, neck, and chest, and also on the arms and hands and the genital area, should alert clinicians to a higher risk of psychological impairments. This may help to better recognize and prevent cumulative life course impairment.
\end{abstract}

Key words: body image, depression, psoriasis, social anxiety, stigmatization.

\section{Introduction}

Psoriasis is a chronic inflammatory skin disease, affecting men and women equally, with an estimated prevalence of $2-3 \%$ in Europeans [1]. Psoriasis may involve all sites of the body, including facial and genital skin. As with other dermatoses, visible disfigurement can serve as a stressor in itself and, furthermore, triggers a negative reaction in others, resulting in feelings of stigmatization [2, 3], which jointly can cause much of the readily measurable psychosocial burden of the disease. Psoriasis strongly affects many facets of patients' quality of life, including physical, psychological, social, sexual, and economic aspects [4-7].
To date, an extensive literature describes the cooccurrence of psoriasis and depression, anxiety, suicidal ideation, and negative body image [6-12]. However, the negative impact of psoriasis on patients' lives, including psychosocial disability, is often unrecognized and under-treated $[13,14]$. This is an important issue to consider, because psychological comorbidities associated with psoriasis have been found to be associated with poor treatment adherence, poor therapeutic response, and inferior outcomes [15-17]. Moreover, it has been found that in patients with psoriasis, depression is associated with increased risk of myocardial infarction, stroke, and cardio-

Address for correspondence: Assoc. Prof. Beata Bergler-Czop MD, PhD, Department of Dermatology, Medical University of Silesia, 20/24 Francuska St, 40-027 Katowice, Poland, phone: +48 501352 033, e-mail: bettina2@tlen.pl Received: 31.05.2016, accepted: 21.07.2016. 
vascular death, especially during acute depression [18]. It is important to better understand key risk factors for psychological impairments associated with psoriasis, which may help to identify individuals who are more vulnerable to the cumulative impact of psoriasis.

Remarkably few data exist on the relationships between anatomical location of psoriatic lesions and psychological comorbidities. Nonetheless, to date, it has been reported that psychiatric morbidities were found to be higher in dermatological patients with lesions localized on the face and/ or hands as compared to the patients without lesions on these parts of the body [19]. It has also been reported that skin lesions on the visible parts of the body were associated with poor physical and mental health in psoriasis patients [20]. Some authors found, however, that patients with psoriasis and atopic dermatitis with genital involvement had significantly higher feelings of stigmatization than those with the visible and the invisible (under clothes) regions affected [21]. In contrast, in one study, no relationship was found between location of psoriatic lesions and feelings and experiences of stigmatization [2]. In sum, relatively few studies have examined the relationships between anatomical location of skin lesions and psychological impairments in psoriasis patients. Furthermore, existing research has included various groups of dermatological patients and the results varied across the studies. It is important to better understand which factors are associated with negative psychological outcomes in psoriasis patients. Knowledge of such factors, and especially of those that can readily be seen by physicians during a routine clinical examination, might facilitate the identification of patients with a higher risk for psychological impairments.

Indeed, although studies that have examined the relationship between site of skin lesions and risk of psychological impairments in patients with psoriasis are sparse, a relationship between the disease severity and mental health has been revealed in many studies. Evidence, however, has demonstrated that clinician-assessed objective severity of psoriasis is not or is poorly associated with psychological outcome variables [22-26]. Magin et al. reported that selfassessed rather than objective severity is associated with psychological burden of skin diseases, and models of association with psychological morbidity in patients with a disease such as psoriasis are likely to be improved by inclusion of self-measured disease severity [26]. The patient's subjective perception of the skin disease does not necessarily align with the perception of the clinician or with objective measures of severity, but may have importance in explaining the psychological burden of the disease. According to these conclusions, in this study we tested associations between self-assessed disease severity and psychological outcomes.

\section{Aim}

The aim of this study was to investigate the importance of location of the skin lesions for experiences of stigmatization, negative body image emotions, social anxiety and depressive symptoms in patients with psoriasis.

\section{Material and methods \\ Participants and procedure}

Subjects were recruited from the Dermatology Clinic of the Silesian Medical University in Katowice, the Polish Association of Psoriasis Patients in Bydgoszcz and the Union of Psoriasis Associations in Poland. Inclusion criteria were age $\geq 18$, psoriasis diagnosed by a dermatologist, at least 1 year of disease duration, and informed consent. Ethical approval was granted by the Ethics Committee of the University of Silesia. The recruitment took place between November 2014 and February 2015.

In total, 193 of 202 received responses fulfilled the criteria adopted in this study. More than one-fifth of the respondents (21.2\%) were members of psoriasis patients' associations. No statistically significant differences were found between the members ( $n=41$ ) vs. the non-members $(n=152)$ regarding socio-demographic, psychological, and psoriasis-related variables (all $p$-values $\geq 0.10$ ).

\section{Measures}

Depression was measured by the Beck Depression Inventory (BDI) $[27,28]$. The $B D I$ is a self-report scale consisting of 21 items. All of the 21 items corresponding to the depressive symptoms are summed to give a single score for the BDI. The total scores can range from 0 to 63 , with higher scores indicating more severe depressive symptoms. The Polish validated version shows good reliability and content validity [29]. A score of 0-11 indicates no or minimal depression; 12-26 indicates mild depression; 27-49 indicates moderate depression; 50-63 indicates severe depression. The reliability of the BDI in the current study was $\alpha=0.92$.

The Social Anxiety Questionnaire (SAQ) is a 12-item, Likert-type self-report measure of social anxiety according to the Clark and Wells' model of social phobia [30]. The SAQ consists of three factors: Symptoms of Social Anxiety (e.g., "The anxiety which I feel in social situations significantly disrupts my occupational or academic functioning and other social activities"), Negative Self-image (e.g., "I think about myself as an ineffectual, socially unattractive person"), and Excessive Processing of the Self as a Social Object (e.g., "During social situations I keep thinking about how I look and how others judge me"). The SAQ shows good psychometric properties [31]. Prior research with this measure has indicated good reliability and construct validity. The SAQ was significantly correlated with anxiety, self-focused rumination, feelings of loneliness and low self-esteem. In the current sample the internal consistency for the SAQ was $\alpha=0.95$, and for the subscales it ranged from 0.87 to 0.89 . 
The Stigmatization Scale is a 6-item scale assessing the experiences and feelings of stigmatization caused by skin diseases [32]. Respondents answered the statements on a 4-grade scale, ranging from 0 (not at all) to 3 (always). The total scores can range from 0 to 18, with higher scores indicating higher levels of stigmatization. Example of an item: "Other people avoid me due to my skin disease". We used the Polish validated version of the scale [33]. The internal consistency of the scale in the current sample was $\alpha=0.88$.

The emotional attitude towards the body was measured using the 9-item Body Emotions Subscale of the Body Ego Questionnaire [34]. Patients answered the statements on a 5-point scale. The Body Emotions Subscale ranges from 9 to 45, with higher scores reflecting a more negative emotional attitude toward the body. An example of an item from the Body Emotions Subscale is as follows: "Sometimes I hate the way I look". In our sample the internal consistency for this subscale was $=0.90$.

Table 1. Baseline characteristics $(N=193)$

\begin{tabular}{|c|c|}
\hline Parameter & Value \\
\hline Age, mean \pm SD [years] & $34.6 \pm 12.1$ \\
\hline \multicolumn{2}{|l|}{ Sex, $n(\%):$} \\
\hline Female & $132(68.4)$ \\
\hline Male & $61(31.6)$ \\
\hline \multicolumn{2}{|l|}{ Education, $n(\%)$ : } \\
\hline Primary & $2(1.0)$ \\
\hline Technical/vocational & $21(11.0)$ \\
\hline Secondary & $85(44.0)$ \\
\hline Higher education & $85(44.0)$ \\
\hline \multicolumn{2}{|l|}{ Marital status, $n(\%)$ : } \\
\hline Single & $62(32.1)$ \\
\hline Married/cohabiting & $104(53.9)$ \\
\hline Divorced & $21(10.9)$ \\
\hline Widowed & $6(3.1)$ \\
\hline \multicolumn{2}{|l|}{ Work, $n(\%)$ : } \\
\hline Employed & $129(66.8)$ \\
\hline Unemployed & $19(9.8)$ \\
\hline Student & $24(12.4)$ \\
\hline Retired & $21(10.9)$ \\
\hline Age at onset of psoriasis, mean \pm SD [years] & $19.6 \pm 10.6$ \\
\hline Duration of psoriasis, mean \pm SD [years] & $16.8 \pm 11.9$ \\
\hline Body surface area (BSA), mean (range) & $21.2(1-82)$ \\
\hline \multicolumn{2}{|l|}{ BSA involvement, $n(\%)$ : } \\
\hline$<5 \%$ & $30(15.5)$ \\
\hline $5-10 \%$ & $52(27.0)$ \\
\hline$>10 \%$ & $111(57.5)$ \\
\hline
\end{tabular}

Sociodemographic data were collected along with baseline disease characteristics such as age at onset of psoriasis, diagnosis by physician, duration of the disease, family history of psoriasis, and self-assessed severity of the disease. The disease severity was defined based on the body surface area (BSA) index. Body surface area is a simple and commonly used instrument referring to the percentage of body surface area involvement [35]. Body surface area is also used as a self-reported measure of the severity of psoriasis [36, 37]. Patients were instructed to estimate psoriasis coverage using the rule of nine and the palmar site of the hand as equivalent to $1 \%$ of the BSA. The respondents reported the surface area of their skin affected by psoriasis including head and neck, arms and hands, chest, abdomen, upper back, lower back, thighs, lower legs and genital area. In general, BSA under $5 \%$ indicates mild involvement, $5-10 \%$ is defined as moderate, and over $10 \%$ is considered severe.

\section{Statistical analysis}

Correlations between variables were calculated using Pearson's correlation coefficient. Group differences were analyzed using the $t$-test and $\chi^{2}$ test. To identify the location of skin lesions associated with psychological impairments four stepwise multiple linear regression models with depression, social anxiety, stigmatization and negative emotional attitude towards the body as dependent variables were performed. All statistical analyses were run under the statistical package Statistica (StatSoft Inc.), version 12 .

\section{Results}

\section{Characteristics of the sample}

The sample consisted of 193 psoriasis patients, and $68.4 \%(n=132)$ of them were women. As shown in Table 1 , participants' age range was $20-67$ years $(M=36.4$ $\pm 12.1)$. The mean age at onset of psoriasis was $19.6 \pm 10.6$ years, varying between 0 and 54 years of age. The mean duration of psoriasis was $16.8 \pm 11.9$ years, varying between 1 and 53 years. Plaque psoriasis was the most common type of psoriasis, which was reported in 175 (90.7\%) cases. More than one-third of the respondents (36.8\%) reported nail involvement. In addition, joint complaints were present in $18.6 \%$ of the patients. Table 2 shows the number of patients with involvement of particular body sites. Almost half of the respondents (48.7\%) reported psoriatic involvement of the genital skin, whereas more than half of the respondents (81.3\%) reported presence of skin lesions on the head and neck (Table 2).

At the time of this study, 84 (43.5\%) patients reported mild, and 31 (16.1\%) patients presented moderate depressive symptoms as defined by the BDI. High levels of social anxiety were observed in 64 (33.2\%) cases. 
Table 2. Correlations between site of psoriatic lesions and depression, social anxiety, experiences of stigmatization and negative emotional attitude to the body

\begin{tabular}{|c|c|c|c|c|c|}
\hline $\begin{array}{l}\text { Involvement of particular } \\
\text { body sites }\end{array}$ & $N(\%)$ & Depression & $\begin{array}{l}\text { Social } \\
\text { anxiety }\end{array}$ & Stigmatization & $\begin{array}{l}\text { Negative emotional } \\
\text { attitude to the body }\end{array}$ \\
\hline Head and neck & $157(81.3)$ & $0.28^{\star \star \star}$ & $0.18^{*}$ & $0.15^{*}$ & $0.25^{\star \star \star}$ \\
\hline Arms and hands & $164(85.0)$ & $0.22^{\star *}$ & 0.13 & $0.34^{\star \star *}$ & $0.27^{\star \star \star}$ \\
\hline Chest & $101(52.3)$ & $0.24^{\star \star}$ & $0.15^{*}$ & $0.33^{\star \star \star}$ & $0.24^{\star \star}$ \\
\hline Abdomen & $111(57.5)$ & $0.19^{\star *}$ & 0.13 & $0.20^{* \star}$ & $0.15^{*}$ \\
\hline Upper back & $98(50.8)$ & $0.25^{\star * *}$ & 0.10 & $0.16^{*}$ & $0.21^{\star \star}$ \\
\hline Lower back & $130(67.4)$ & $0.19^{\star \star}$ & 0.12 & $0.26^{\star * \star}$ & $0.23^{\star *}$ \\
\hline Thighs & $108(56.0)$ & 0.13 & 0.13 & $0.28^{\star * *}$ & $0.21^{\star \star}$ \\
\hline Knees, lower legs, ankles & $117(60.6)$ & $0.16^{*}$ & 0.05 & $0.26^{\star * *}$ & $0.17^{\star}$ \\
\hline Genital area & $94(48.7)$ & $0.25^{\star \star \star}$ & 0.13 & $0.16^{*}$ & $0.22^{\star \star}$ \\
\hline BSA total & $193(100)$ & $0.28^{\star * *}$ & $0.15^{*}$ & $0.31^{\star * *}$ & $0.30^{* * *}$ \\
\hline
\end{tabular}

${ }^{* * *} p<0.001,{ }^{* *} p<0.01,{ }^{*} p<0.05$.

\section{Associations between location of skin lesions and psychological outcomes}

Psoriatic involvement of all investigated parts of the body was statistically significantly related to feelings of stigmatization and negative emotional attitude towards the body. As shown in Table 2, the strongest association was observed between experiences of stigmatization and presence of psoriatic lesions on the arms and hands $(r=0.34 ; p<0.0001)$, and the chest $(r=0.33 ; p<0.0001)$. The negative emotional attitude towards the body was most closely related to the presence of lesions on the arms and hands ( $r=0.27 ; p<0.0001)$, the head and neck $(r=0.25 ; p<0.0001)$, and the chest $(r=0.24 ; p<0.001)$. Depressive symptoms were significantly related to the presence of skin lesions on the head and neck $(r=0.28$; $p<0.0001)$, the genital skin $(r=0.25 ; p<0.0001)$, and the upper back $(r=0.25 ; p<0.0001)$. Social anxiety was significantly associated with the presence of psoriatic lesions on the head and neck $(r=0.18 ; p<0.05)$, and the chest $(r=0.15 ; p<0.05)$. Moreover, subjective severity of the disease based on body surface area involvement was significantly associated with all of the psychological outcome variables (Table 2). Correlation coefficients ranged from 0.15 to $0.31(p<0.05)$.

To examine the relative contribution of location of psoriatic lesions to depression, social anxiety, negative emotional attitude towards the body and stigmatization, four stepwise multiple linear regressions were performed. The results are presented in Table 3. As shown in this table, the location of psoriatic lesions on the head and neck $(p<0.01)$, the genital skin $(p<0.05)$, and on the arms and hands ( $p<0.05)$ was most closely associated with depression, accounting for $12 \%$ of the variance. The main contributor to depression was the presence of lesions on the head and neck, accounting for $8 \%$ of the variance in the BDI scores.
Regression analysis for social anxiety revealed that only the location of psoriatic lesions on the head and neck was statistically significant in accounting for the variance of this variable (approximately 3\%). Other body regions did not reach statistical significance.

Regression analysis for feelings of stigmatization indicated that the location of psoriatic lesions on the arms and hands $(p<0.01)$, and the chest $(p<0.01)$ was statistically significant in accounting for the variance (approximately $15 \%$ of explained variance).

Regression analysis revealed that the main contributors to the negative emotional attitude towards the body were the presence of skin lesions on the arms and hands $(p<0.01)$, and presence on the head and neck $(p<0.01)$, accounting for $12 \%$ of the variance.

\section{Discussion}

Although there is strong evidence for the link between psoriasis and psychological disorders [6-10] relatively few studies have examined the relationships between anatomical location of skin lesions and psychological comorbidities in patients with psoriasis. The results of the present study highlight the importance of the occurrence of lesions in different body regions for feelings and experiences of stigmatization, negative emotional attitude towards the body, social anxiety and depressive symptoms. The location of psoriatic lesions on the head and neck was the main contributor to depression, social anxiety and negative emotional attitude to the body. The location of lesions on the arms and hands was a significant contributor to feelings of stigmatization, negative emotional attitude toward the body, and depression. Additionally, the genital involvement makes a significant contribution to the variance in depression, whereas the presence of psoriatic lesions on the chest 
Table 3. Results from four multiple linear regression models with depression, social anxiety, stigmatization and negative emotional attitude toward the body as dependent variables

\begin{tabular}{|c|c|c|c|c|c|c|}
\hline Variable & $\beta$ & $\Delta R^{2}$ & $F \Delta R^{2}$ & $F$ & $R^{2}$ & Adj. $R^{2}$ \\
\hline Depression: & & & & $9.71^{\star \star \star}$ & 0.14 & 0.12 \\
\hline Head and neck & $0.23^{\star *}$ & 0.08 & $15.75^{\star \star \star}$ & & & \\
\hline Genital area & $0.16^{*}$ & 0.04 & $7.78^{\star *}$ & & & \\
\hline Arms and hands & $0.15^{*}$ & 0.02 & $4.58^{*}$ & & & \\
\hline Social anxiety: & & & & $4.30^{*}$ & 0.04 & 0.03 \\
\hline Head and neck & $0.17^{*}$ & 0.03 & $5.95^{\star}$ & & & \\
\hline Chest & 0.11 & 0.01 & 2.59 & & & \\
\hline Stigmatization: & & & & $17.57^{\star * *}$ & 0.16 & 0.15 \\
\hline Arms and hands & $0.24^{\star *}$ & 0.11 & $24.33^{* * *}$ & & & \\
\hline Chest & $0.23^{\star *}$ & 0.05 & $9.69^{\star *}$ & & & \\
\hline Negative emotional attitude to the body: & & & & $9.74^{\star \star \star}$ & 0.14 & 0.12 \\
\hline Arms and hands & $0.22^{\star *}$ & 0.08 & $15.21^{\star \star *}$ & & & \\
\hline Head and neck & $0.20^{* *}$ & 0.05 & $10.90^{\star \star}$ & & & \\
\hline Genital area & 0.11 & 0.01 & 2.14 & & & \\
\hline
\end{tabular}

${ }^{* \star *} p<0.001,{ }^{* *} p<0.01,{ }^{*} p<0.05$.

was a significant contributor to experiences of stigmatization. Moreover, according to current knowledge [6-10], our results show high rates of psychological impairments in patients with psoriasis. In this study $16.1 \%$ of patients reported moderate depressive symptoms. Mild depressive symptoms were present in $43.5 \%$ of the patients. Furthermore, high levels of social anxiety were observed in $33.2 \%$ of the respondents.

To date, only a few studies have been conducted on the relationship between location of psoriatic lesions and psychological impairment in patients with psoriasis. However, it has been reported that patients with visible psoriatic lesions reported poorer physical and mental health [20], which is consistent with the findings of our study. In addition, our results are in agreement with the findings reported by Picardi et al. [19], who found that in dermatological patients the presence of skin lesions localized on the face and hands is associated with a very large increase in the prevalence of psychiatric disorders. Furthermore, our results indicated that genital involvement may be a risk factor for depression in patients with psoriasis. We also detected that the genital involvement is significantly related to feelings of stigmatization, which is consistent with previous research, where dermatological patients with genital lesions felt significantly more stigmatized than those without genital skin affected [21]. Moreover, these results are also in line with previous findings highlighting the association between the involvement of the genital area and poor quality of life, higher levels of psychological distress, and sexual dysfunction [38-40].

The unique contribution of this study is the analysis of patients' subjective perceptions of their skin disease that allowed for identification of psychologically sensitive anatomic locations of skin lesions associated with feelings of stigmatization, depressive symptoms, negative body-related emotions, and social anxiety. However, our results need to be viewed in the light of several limitations. First, our study was cross-sectional; therefore, we cannot prove causality, and the findings need to be replicated in a prospective study. Second, women are overrepresented in our sample (68.4\% as opposed to $32.6 \%)$, which may limit the generalizability of the results. Moreover, our sample also included the members of psoriasis patients' associations (21.2\% of the sample). It may be speculated that these patients may have (by the very fact of their membership) considerable concern regarding their disease or they might suffer from more severe psoriasis and/or have a greater psychosocial burden of the disease. However, in this study no significant differences were found between the members vs. the non-members. Finally, a limitation of this study is the exclusive reliance on the self-report questionnaires. Future research could extend our findings by including both clinician-assessed location and severity of psoriatic lesions and those selfassessed by patients.

\section{Conclusions}

We identified 'sensitive' body regions affected by psoriasis associated with negative mental health, including symptoms of depression, social anxiety, negative emotions about one's own appearance, and feelings of stigmatization. The most important result of our study is that the presence of psoriatic lesions on the head, neck, 
and chest, and also on the arms and hands and in the genital area, should alert clinicians to the higher risk for psychological impairments in patients with psoriasis. This may help to better recognize the problem and earlier in the disease course provide patients comprehensive management to prevent cumulative life course impairment in psoriasis. Future research should aim to further explore the nature of the relationship between site of skin lesions and psychological impairments in patients with psoriasis.

\section{Acknowledgments}

The authors thank the Polish Association of Psoriasis Patients in Bydgoszcz and the Union of Psoriasis Associations in Poland.

\section{Conflict of interest}

The authors declare no conflict of interest.

\section{References}

1. Parisi R, Symmons DPM, Griffiths CEM, Ashcroft DM. Global epidemiology of psoriasis: a systematic review of incidence and prevalence. J Invest Dermatol 2013; 133: 377-85.

2. Hrehorów E, Salomon J, Matusiak L, et al. Patients with psoriasis feel stigmatized. Acta Derm Venereol 2012; 92: 67-72.

3. Łakuta P, Marcinkiewicz K, Bergler-Czop B, BrzezińskaWcisło L. How does stigma affect people with psoriasis? Adv Dermatol Allergol 2017; 34: 36-41.

4. Ayala F, Sampogna F, Romano GV, et al. The impact of psoriasis on work-related problems: a multicenter cross-sectional survey. J Eur Acad Dermatol Venereol 2014; 28: 1623-32.

5. Bewley A, Burrage DM, Ersser SJ, et al. Identifying individual psychosocial and adherence support needs in patients with psoriasis: a multinational two-stage qualitative and quantitative study. J Eur Acad Dermatol Venereol 2014; 28: 763-70.

6. Kimball A, Gieler U, Linder D, et al. Psoriasis: is the impairment to a patient's life cumulative? J Eur Acad Dermatol Venereol 2010; 24: 989-1004.

7. Warren RB, Kleyn CE, Gulliver WP. Cumulative life course impairment in psoriasis: patient perception of disease-related impairment throughout the life course. Br J Dermatol 2011; 164 Suppl 1: 1-14.

8. Cohen BE, Martires KJ, Ho RS. Psoriasis and the risk of depression in the US Population: National Health and Nutrition Examination Survey 2009-2012. JAMA Dermatol 2016; 152: 73-9.

9. Dalgard FJ, Gieler U, Tomas-Aragones L, et al. The psychological burden of skin diseases: a cross-sectional multicenter study among dermatological out-patients in 13 European countries. J Invest Dermatol 2015; 135: 984-91.

10. Schmitt J, Ford DE. Psoriasis is independently associated with psychiatric morbidity and adverse cardiovascular risk factors, but not with cardiovascular events in a population based sample. J Eur Acad Dermatol Venereol 2010; 24: 88592.

11. Magin P, Adams J, Heading G, et al. The psychological sequelae of psoriasis: results of a qualitative study. Psychol Health Med 2009; 14: 150-61.
12. Magin P, Heading G, Adams J, Pond D. Sex and the skin: a qualitative study of patients with acne, psoriasis and atopic eczema. Psychol Health Med 2010; 15: 454-62.

13. Moon HS, Mizara A, McBride SR. Psoriasis and psycho-dermatology. Dermatol Ther (Heidelb) 2013; 3: 117-30.

14. Bundy C, Borthwick M, McAteer H, et al. Psoriasis: snapshots of the unspoken: using novel methods to explore patients' personal models of psoriasis and the impact on well-being. Br J Dermatol 2014; 171: 825-31.

15. Renzi C, Picardi A, Abeni D, et al. Association of dissatisfaction with care and psychiatric morbidity with poor treatment compliance. Arch Dermatol 2002; 138: 337-42.

16. Fortune DG, Richards HL, Kirby B, et al. Psychological distress impairs clearance of psoriasis in patients treated with photochemotherapy. Arch Dermatol 2003; 139: 752-6.

17. Verhoeven EW, Kraaimaat FW, de Jong EM, et al. Individual differences in the effect of daily stressors on psoriasis: a prospective study. Br J Dermatol 2009; 161: 295-9.

18. Egeberg A, Khalid U, Gislason GH, et al. Impact of depression on risk of myocardial infarction, stroke and cardiovascular death in patients with psoriasis: a Danish Nationwide Study. Acta Derm Venereol 2016; 96: 218-21.

19. Picardi A, Abeni D, Renzi C, et al. Increased psychiatric morbidity in female outpatients with skin lesions on visible parts of the body. Acta Derm Venereol 2001; 81: 410-4.

20. Fortune DG, Main CJ, O'Sullivan TM, Griffiths CE. Quality of life in patients with psoriasis: the contribution of clinical variables and psoriasis-specific stress. Br I Dermatol 1997; 137: 755-60.

21. Schmid-Ott G, Kuensebeck HW, Jaeger B, et al. Validity study for the stigmatization experience in atopic dermatitis and psoriatic patients. Acta Derm Venereol 1999; 79: 443-7.

22. Finzi A, Colombo D, Caputo A et al. Psychological distress and coping strategies in patients with psoriasis: The PSYCHAE Study. J Eur Acad Dermatol Venereol 2007; 21: 1161-9.

23. Janowski K, Steuden S, Pietrzak A, et al. Social support and adaptation to the disease in men and women with psoriasis. Arch Dermatol Res 2012; 304: 421-32.

24. Fortune DG, Richards HL, Griffiths CE, Main CJ. Psychological stress, distress and disability in patients with psoriasis: consensus and variation in the contribution of illness perceptions, coping and alexithymia. Br J Clin Psychol 2002; 41: 157-74.

25. Richards HL, Fortune DG, Griffiths CE, Main CJ. The contribution of perceptions of stigmatisation to disability in patients with psoriasis. J Psychosom Res 2001; 50: 11-5.

26. Magin PJ, Pond CD, Smith WT, et al. Correlation and agreement of self-assessed and objective skin disease severity in a cross-sectional study of patients with acne, psoriasis, and atopic eczema. Int J Dermatol 2011; 50: 1486-90.

27. Beck AT, Ward CH, Mendelson M, et al. An inventory for measuring depression. Arch Gen Psychiatry 1961; 4: 561-71.

28. Beck AT, Steer RA, Garbin MG. Psychometric properties of the Beck Depression Inventory: twenty-five years of evaluation. Clin Psychol Rev 1988; 8: 77-100.

29. Parnowski T, Jernajczyk W. Inwentarz Depresji Becka w ocenie nastroju osób zdrowych i chorych na choroby afektywne. [Beck's Depression Inventory in the rating of mood in normal subjects and in patients with affective disturbances]. Psychiatr Pol 1977; 11: 417-25.

30. Clark DM, Wells A. A cognitive model of social phobia. In: Social Phobia: Diagnosis, Assessment and Treatment. Heim- 
berg R, Liebowitz M, Hope DA, Schneier FR (eds). Guilford Press, New York 1995; 69-93.

31. Łakuta P. Psychometric properties of the Social Anxiety Questionnaire. Department of Psychology, University of Silesia in Katowice; 2015 (Unpublished report).

32. Lu Y, Duller P, van der Valk PGM, Evers AWM. Helplessness as predictor of perceived stigmatization in patients with psoriasis and atopic dermatitis. Dermatol Psychosom 2003; 4: 146-50.

33. Hrehorów E, Szepietowski J, Reich A, et al. Instruments for stigmatization evaluation in patients suffering from psoriasis: Polish language version. Dermatol Klin 2006; 8: 253-8.

34. Sakson-Obada O. Pamięć ciała. Ja cielesne w relacji przywiązania i w traumie. [Memory of a body. Body ego in trauma and attachment relationship]. Diffin, Warsaw 2009.

35. Szepietowski J, Adamski Z, Chodorowska G, et al. Leczenie łuszczycy zwyczajnej - rekomendacje ekspertów Polskiego Towarzystwa Dermatologicznego. Część I: łuszczyca łagodna, łuszczyca wieku dziecięcego. [Diagnostics and treatment of psoriasis vulgaris: guidelines of the Polish Dermatological Society. Part I: mild psoriasis, psoriasis in children]. Przegl Dermatol 2012; 99: 83-96.

36. Dubertret L, Mrowietz U, Ranki A, et al. European patient perspectives on the impact of psoriasis: the EUROPSO patient membership survey. Br J Dermatol 2006; 155: 729-36.

37. Schmitt JM, Ford DE. Role of depression in quality of life for patients with psoriasis. Dermatology 2007; 215: 17-27.

38. Meeuwis KA, de Hullu JA, de Jager ME, et al. Genital psoriasis: a questionnaire-based survey on a concealed skin disease in the Netherlands. J Eur Acad Dermatol Venereol 2010; 24: 1425-30.

39. Ryan C, Sadlier M, Menter A, et al. Genital psoriasis is as sociated with significant impairment in quality of life and sexual functioning. I Am Acad Dermatol 2015; 72: 978-83.

40. Molina-Leyva A, Jiménez-Moleón JJ, Naranjo-Sintes R, RuizCarrascosa JC. Sexual dysfunction in psoriasis: a systematic review. J Eur Acad Dermatol Venereol 2015; 29: 649-55. 